Journal of Advanced Research in Fluid Mechanics and Thermal Sciences

\title{
Automatic Temperature Measurement and Monitoring System for Milling Process of AA6041 Aluminum Aloy using MLX90614 Infrared Thermometer Sensor with Arduino
}

\author{
Agus Sudianto ${ }^{1,2}$, Zamberi Jamaludin ${ }^{1,}{ }^{*}$, Azrul Azwan Abdul Rahman ${ }^{1}$, Sentot Novianto ${ }^{3}$, Fajar \\ Muharrom $^{4}$ \\ 1 Smart Factory System Research Group, Fakulti Kejuruteraan Pembuatan, Universiti Teknikal Malaysia Melaka, Hang Tuah Jaya, 76100 Durian \\ Tunggal, Melaka, Malaysia \\ 2 Mechanical Engineering Department, STT YBS Internasional, Jln. Pasar Wetan, Kompleks Mayasari Plasa, 46123 Kota Tasikmalaya, West Java, \\ Indonesia \\ 3 Department of Mechanical Engineering, Faculty of Industrial Technology, Universitas Trisakti, Jakarta 16424, Indonesia \\ 4 Faculty of Ingenieurwissenschaften, Universitaet Duisburg-Essen, Forsthausweg 2 Duisburg 47057, North Rheine Westphalia, Germany
}

\section{ARTICLE INFO}

\section{Article history:}

Received 25 August 2020

Received in revised form 10 January 2021

Accepted 13 January 2021

Available online 30 April 2021

\section{Keywords:}

Milling process; Arduino MLX90614 infrared thermometer; fluke Ti400 infrared fusion; smart measurement

\section{ABSTRACT}

Manufacturing process of metal part requires real-time temperature monitoring capability to ensure high surface integrity is upheld throughout the machining process. A smart temperature measurement and monitoring system for manufacturing process of metal parts is necessary to meet quality and productivity requirements. A smart temperature measurement can be applied in machining processes of conventional, non-conventional and computer numerical control (CNC) machines. Currently, an infrared fusion based thermometer Fluke Ti400 was employed for temperature measurement in a machining process. However, measured temperature in the form of data list with adjustable time range setting is not automatically linked to the computer for continuous monitoring and data analysis purposes. For this reason, a smart temperature measurement system was developed for a CNC milling operation on aluminum alloy (AA6041) using a MLX90614 infrared thermometer sensor operated by Arduino. The system enables data linkages with the computer because MLX90614 is compatible and linked to Microsoft Exel via the Arduino. This paper presents a workstudy on the performance of this Arduino based temperature measurement system for dry milling process application. Here, the Arduino based temperature measurement system captured the workpiece temperature during machining of Aluminum Alloy (AA6041) and data were compared with the Fluke Ti400 infrared thermometer. Measurement results from both devices showed similar accuracy level with a deviation of $\pm 2{ }^{\circ} \mathrm{C}$. Hence, a smart temperature measurement system was succeesfully developed expanding the scopes of current system setup.

\footnotetext{
* Corresponding author.

E-mail address: zamberi@utem.edu.my
}

https://doi.org/10.37934/arfmts.82.2.114 


\section{Introduction}

Monitoring of temperature during cutting process in manufacturing production is very important. Extreme temperature and sudden deviation will cause changes in product behavior especially the part surface integrity. Additional precaution is necessary regarding temperature rise due to the impact of the machining process [1] as it has negative consequences on the machining characteristic such as surface roughness especially for Aluminum-based materials [2]. The cutting tool performance is certainly dependent on the stability of the geometry, the effectiveness working and thermal conductivity against the material processes that are either ferrous or non-ferrous. A temperature measuring system can monitor any temperature change during the machining process. Through Information and Communication Technology (ICT), tools such as cloud computing including robotics, Internet of Things (IOT) and machine learning have emerged as possible solutions for temperature monitoring system application in machining process. These enable technologies are necessary for development of smart manufacturing process capable of addressing needs such as improve quality, reduce time, increase in customized requirements and price affordibily [3-5]. For example, in a supply change management system, infrared thermometer was used to measure the temperature with alarm activated if the measured temperature is out of the range.

An MLX90614 infrared thermometer is a contactless temperature sensor module for Arduino compatible device. An infrared thermometer works to measure the object temperature by the infrared radiation in the form of an electromagnetic wave through the light emitted on the object. MLX90614 is a powerful 17-bit ADC infrared sensing device with a very low noise amplifier. It utilizes non-contact temperature sensing to collect the temperature information without any surface contact of the object at high accuracy and resolution. The sensor was calibrated with a digital System Management Bus (SMBus) from the factory in wide temperature ranges: $-40{ }^{\circ} \mathrm{C}$ to $125{ }^{\circ} \mathrm{C}$ for the ambient temperature and $-70^{\circ} \mathrm{C}$ to $380^{\circ} \mathrm{C}$ for the object temperature with standard accuracy of \pm 0.5 ${ }^{\circ} \mathrm{C}$ around room temperatures.

Arduino possesses the technology of high-speed digital signal processing, minor cable wiring in communicating, thus provides users with a convenient, rapid, effective and efficient automization method [6].The integration of MLX 90614 Infrared Thermometer with Arduino then linked the measured temperature data with the Microsoft Excel resulting in contactless and realt-time temperature measurement, more convenient retrieval and subsequent analyses of the data [7]. MLX90614 was used to study the effect of distance and environment against the reading of the measurement results [8]. It was also applied with microprocessor STM32F107 for studies on temperature difference measurement using bottles through shapes and dimensions [9]. It was also used in a small drone carrying the MLX90614 infrared sensor to produce a fast temperature sensing scheme for inaccessible areas aims to facilitate the detection of heat loss inside buildings, thus overcoming the require manual labor as well as the use of expensive instrumentation [10]. A set of low cost Black Globe Thermometers (BGT) was applied to observethe black globe temperature estimation and response time depends on stimuli of the transducer, materials and globe diameters based on the Arduino open-source platform with MLX90614 digital infrared thermometer [11]. Also, MLX90614 was utilized as a passive infrared sensor to receive infrared energy in diagnosing patients [12].

Arduino has also been widely used in various fields including medicine [13] such as to develop heart rate and body temperature monitoring system [14], heart diseases, diabetes etc. It was also applied in power systems such as plantations thermal generator [15], crop health monitoring and household devices [16]. 
Therefore, knowledge of microcontrollers can be integrated and synchronize with various loTbased sensors through the Arduino program. In the field of manufacturing especially machining process, microcontroller devices can link the collected data to the Microsoft excel for online monitoring and data analysis thus producing a smart system monitoring devices. The system is not yet employed in machining application thus providing machine tool developers and researchers with the ability for contactless temperature measurements and automatic data analysis. Therefore, in this paper, the infrared thermometer sensor of MLX90614 with Arduino was applied as a smart measuring and monitoring system on a milling process providing accurate data while ensuring high quality product outcomes. Author utilizes this system in drying machining condition for measuring the temperature of processed material, especially for aluminum alloy (AA6041) and other non-ferro materials.

This paper is arranged as follows; section 2 introduces the working principle of MLX90614 infrared thermometer, Arduino and Fluke Ti400 applied in milling process of AA6041. In Section 3, discussions were made on the result of temperature measurement comparing results obtained using MLX90614 with Fluke Ti400 infrared fusion. Finally, section 4 concludes the findings obtained.

\section{Materials and Method}

The working principle of an infrared thermometer is based on black body radiation, whereby, any material at temperatures above absolute zero hass movement of molecules within it. Molecules move faster when the temperature is higher. Molecules emit infrared radiation when they move, and emit more radiation, including visible light, when they become hotter. Below is a basic measurement equation for Infrared Thermometry

$S(T)=\varepsilon S\left(T_{S U R F}\right)+(1-\varepsilon) S\left(T_{B G}\right)$

Eq. (1) elucidates both the background temperature $\left(T_{B G}\right)$ and the temperature of the object being measured (TsuRF) influenced by the signal for any measurement. While Sakuma-Hattori Equation in Eq. (2) below revealed the problematic for the usage of handheld industrial type instruments like handphones. These instruments did not provide the $A, B$ and $C$ constants as in the equation.

$L(\lambda, T)=\frac{C_{1 L}}{\lambda^{5}\left[\exp \left(\frac{c_{2}}{\lambda T}\right)-1\right]}$

Also, the Wien's Displacement, Planck and Stefan-Boltzmann equation described the peak wavelength for a given temperature. The wavelength was influenced by temperature as is shown in Figure 1. The Wien's Displacement Law states that

$\lambda_{\max } T=c_{3}$

Planck's Law

$S=\frac{C}{\exp \left(\frac{c_{2}}{A T+B}\right)}$ 


\section{Stefan-Boltzmann Law}

$M=\sigma T^{4}=\pi \int_{0}^{\infty} L(\lambda, T) d \lambda$

For all the above equations

$S=$ readout radiance measurement from the radiometric reference

$T=$ temperature

$\mathrm{T}_{\text {SURF }}=$ temperature of the object being measured

$\mathrm{T}_{\mathrm{BG}} \quad$ = background temperature

$\lambda \quad=$ wavelength

$\varepsilon \quad=$ emissivity

$A, B, C=$ calibration constants from radiometric reference

$M \quad$ = electromagnetic spectrum

$\sigma \quad=$ energy

$\mathrm{L} \quad=$ spectral radiance

Figure 1 below shows the relationship between Planck's Law and Wien's Displacement Law. Note that the peak energy for the Sun is around $0.5 \mu \mathrm{m}$ while at room temperatureit is below $10 \mu \mathrm{m}$. Three other issues that require consideration for infrared thermometer treatment are; (i) exposure to thermal shock, (ii) measurement conditions, and (iii)influence of optical hygiene.

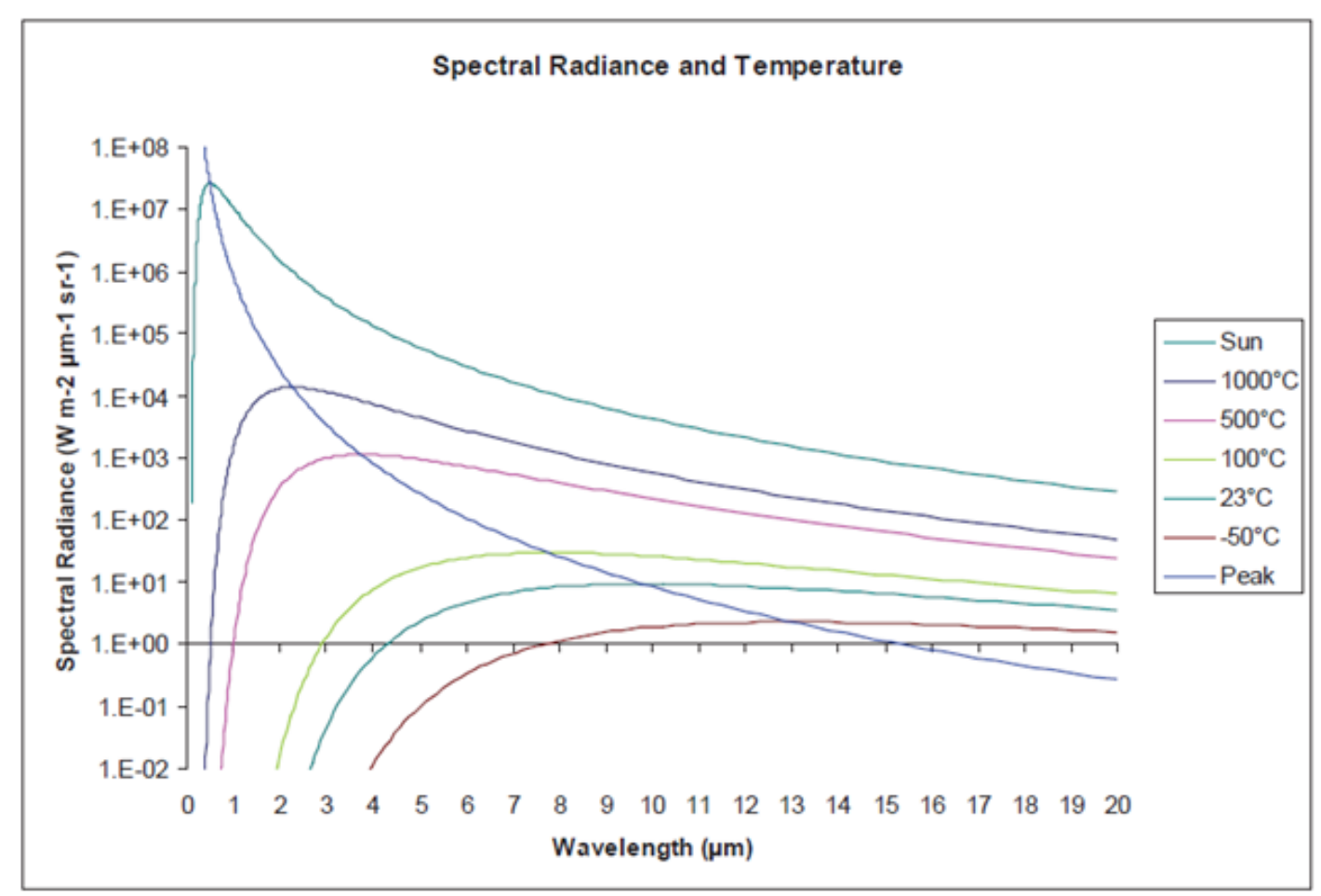

Fig. 1. The relation between Planck's Law and Wien's Displacement Law [14] 


\subsection{Measurements}

This section compares MLX90614 infrared thermometer to FLUKE Ti400 infrared fusion thermometer.

\subsubsection{MLX90614 infrared contactless thermometer}

The MLX90614 shown in Figure 2 measures the temperature of an object without coming into contact with the object using both emissivity and radiation as a mean of measurement. Emissivity is a coefficient that shows how well an object emits infrared radiation compared to a theoretically perfect black body. This radiation is used by MLX90614 to calculate the object temperature. During manufacturing, MLX90614 is calibrated with the black matter with an emissivity of $99.9 \%$ which is considered to be $E=1$. Table 1 details the specifications of MLX90614 infrared thermometer.

Table 1

Detail description of MLX90614 infrared thermometer specifications

\begin{tabular}{lll}
\hline Attribute & Value & Unit \\
\hline Ambient Temperature Range & -40 to 125 & ${ }^{\circ} \mathrm{C}$ \\
Object Temperature Range & -70 to 380 & ${ }^{\circ} \mathrm{C}$ \\
Detector Resolution & 0.02 & ${ }^{\circ} \mathrm{C}$ \\
Versions & Single and dual-zone & \\
Application & Arduino, SMBus compatible digital interface \\
Model Number & MLX90614 & \\
Measurement Resolution & 0.02 & ${ }^{\circ} \mathrm{C}$ \\
Best Temperature Measurement Accuracy & 0.5 & ${ }^{\circ} \mathrm{C}$ \\
Focus Type & Manual & \\
Version & 3 and 5 & $\mathrm{~V}$ \\
Display Size & LCD $16 \times 2$ & $\mathrm{Cm}$ \\
Weight & $<250$ & $\mathrm{gram}$ \\
Price & Cheive & \\
\hline
\end{tabular}

The MLX90614 Infrared Thermometer needs to be connected to the Arduino. Setting up for the connection of the MLX90614 sensor include

i. Arduino

ii. Character LCD $16 \times 2$

iii. MLX90614

iv. LCD Shield

In order to communicate with the Arduino unit, programming codes are necessary. The temperature measurement programming codes for the MLX90614 infrared thermometer compatible to Arduino is presented in the annexure of this paper. The program dictates that the actual temperature measurement is in Celsius degree and read the value on the LCD screen. Simultaneously the data is delivered every 1000 milliseconds into the Microsoft Excel.

\subsubsection{Fluke Ti400 infrared fusion temperature measurement}

The detailed data description in Table 2 below is a specification of the Fluke Ti400 infrared fusion. 


\section{Table 2}

Detail description of Fluke Ti400 Infrared Fusion specification

\begin{tabular}{lll}
\hline Attribute & Value & Unit \\
\hline Temperature Measurement Range & -20 to +1200 & ${ }^{\circ} \mathrm{C}$ \\
Detector Resolution & $320 \times 240$ & pixel \\
Display Resolution & $640 \times 480$ & pixel \\
Application & Thermography & \\
Model Number & Tl400 & \\
Thermal Sensitivity & 0.05 & ${ }^{\circ} \mathrm{C}$ \\
Best Temperature Measurement Accuracy & \pm 2 & ${ }^{\circ} \mathrm{C}$ \\
Focus Type & Automatic, Manual & \\
Refresh Rate & 9 & $\mathrm{~Hz}$ \\
Minimum Focus Distance & 15 & $\mathrm{~cm}$ \\
Display Size & 3.5 & $\mathrm{inch}$ \\
Weight & 1 & $\mathrm{~kg}$ \\
\hline
\end{tabular}

\subsection{Methodology}

Figure 2 illustrates the methodology applied for this research work. The first part of the experiment consists of the sensor temperature readings validation. Here, the temperature measurements of MLX90614 Infrared Thermometer were compared with the Fluke Ti400 Infrared Fusion. The process starts with sample preparation that included a heater for heating specimen AA6041, two measurement devices and a personal computer or laptop to gather the temperature data. Temperature measurements were recorded simultaneously using MLX90614 and Ti400 by adjusting the emissivity values of both measurement units at nine different temperatures. Finally, the measured data were analyzed as in Figure 3.

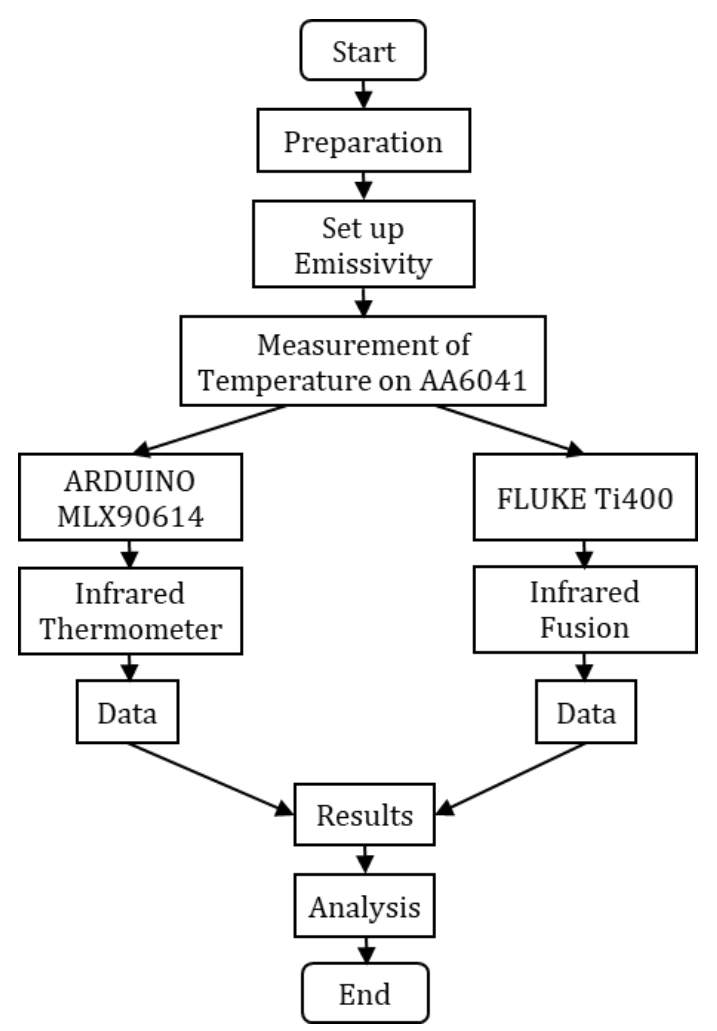

Fig. 2. Temperature validation measurement 
Figure 3 describes the process flow on AA6041, which involved machining parameters such as cutting speed, feeding speed, depth of cut, width of cut, flute and tool angle.

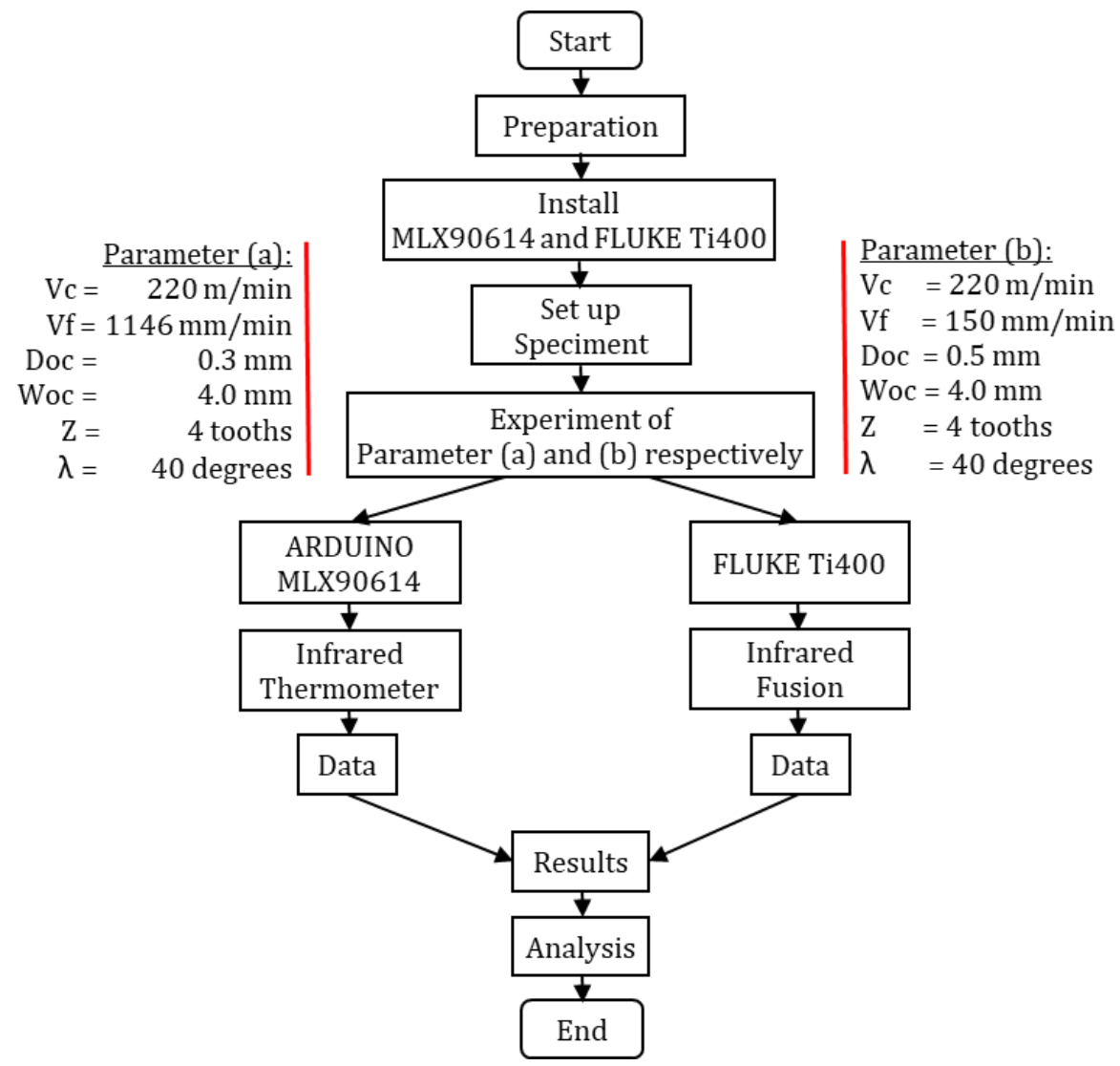

Fig. 3. Milling process temperature measurement

\subsubsection{Measurement preparation}

The followings illustrate measurement preparations that were performed using the MLX90614 Infrared Thermometer with AA6041 specimen. The steps consisted of

i. Specimen AA6041 as shown in Figure 4 was heated to nine different temperatures and data were recorded using MLX90614 and Fluke Ti400 three times continuously. The heat employed was from temperature range of $60^{\circ} \mathrm{C}$ to $225^{\circ} \mathrm{C}$.

ii. MLX 90614 Infrared Thermometer as in Figure 5(a) was linked to Microsoft Excel for data recording.

iii. The Fluke Ti400 Infrared Fusion $9 \mathrm{~Hz}$ as shown in Figure 5(b) recorded the temperature in graphical form and videos. 


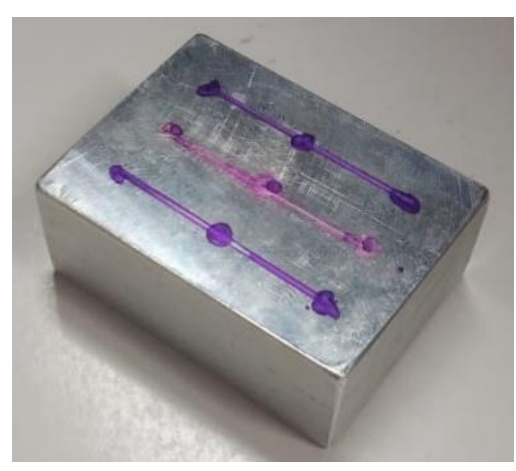

Fig. 4. Specimen AA6041, size of $50 \times 38 \times 20$ in $\mathrm{mm}$

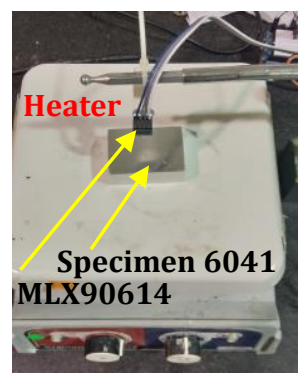

(a)

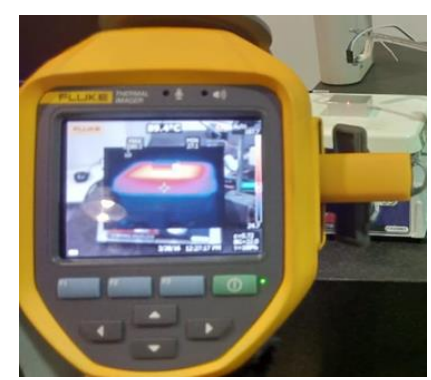

(b)

Fig. 5. (a) Temperature measurement using MLX90614 infrared thermometer (b) Temperature measurement using Fluke Ti400 infrared fusion thermometer

\subsubsection{Experimental design for temperature measurement}

This first part of this section describes the experimental design set up for validating the temperature measurement of MLX90614 against Fluke Ti400. In the second part, the temperature measurements were recorded on the milling machining process.

\subsubsection{Validation for temperature measurement on AA6041}

A total of nine sets of temperature measurements were recorded on the AA6041 object whereby these measurements were repeated three times. The measurements were performed gradually from low temperatures of $68^{\circ} \mathrm{C}$ to high temperatures of close to $220^{\circ} \mathrm{C}$. Figure 6 shows the experimental measurement setup employing (a) MLX90614 and (b) Fluke Ti400.

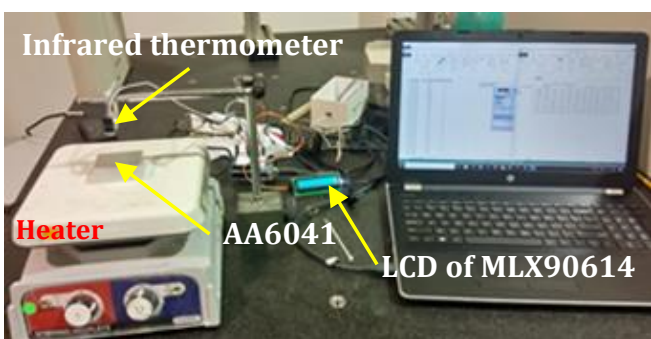

(a)

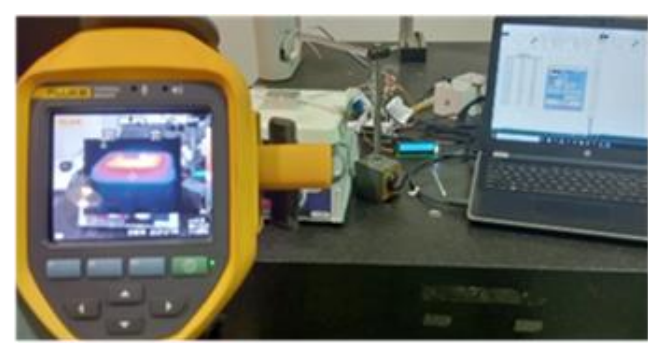

(b)

Fig. 6. (a) The temperature measurement by MLX90614 (b) The temperature measurement by Fluke Ti400 
A similar experimental setup was applied by [17] who monitored the steel plate temperatures employing an MLX90614 infrared sensor with Arduino and the help of the RF433Mhz module.

\subsubsection{Measurement of temperature on AA6041 in milling process}

Figure 7 below shows the milling operation involving the HPMT S42 1000072 as a cutting tool on the AA6041 by down milling process at $7006 \mathrm{rpm}$. The heat generated in the AA6041 was measured by the MLX90614 infrared thermometer, then the temperature data appeared in the LCD display of MLX90614 that were recorded in a laptop through Arduino and linked to the Microsoft Excel.

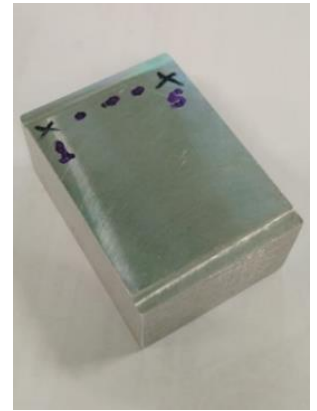

(a)

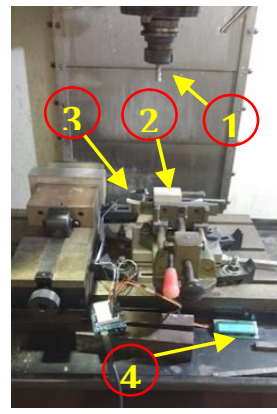

(b)

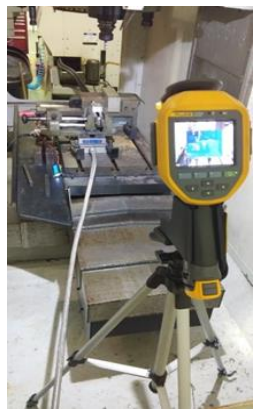

(c)
(1) is a cutting tool HPMT S42 1000072 (2) is an AA6041 specimen (3) is an infrared thermometer (4) is a screen LCD of MLX90614

Fig. 7. (a) Specimen milling (b) Temperature measurement by MLX90614 consisting of the cutting tool, specimen, infrared thermometer and LCD display and (c) temperature measurement by fluke Ti400

The temperature data measured using Fluke was stored in the Fluke memory in the form of images or videos. Figure 8(a) shows the experimental setup used. The yellow dotted line and the red dotted line in Figure $8(\mathrm{~b})$ illustrate the sides that was prepared for the milling process with respect to measurement-1 and measurement- 2 parameters respectively.

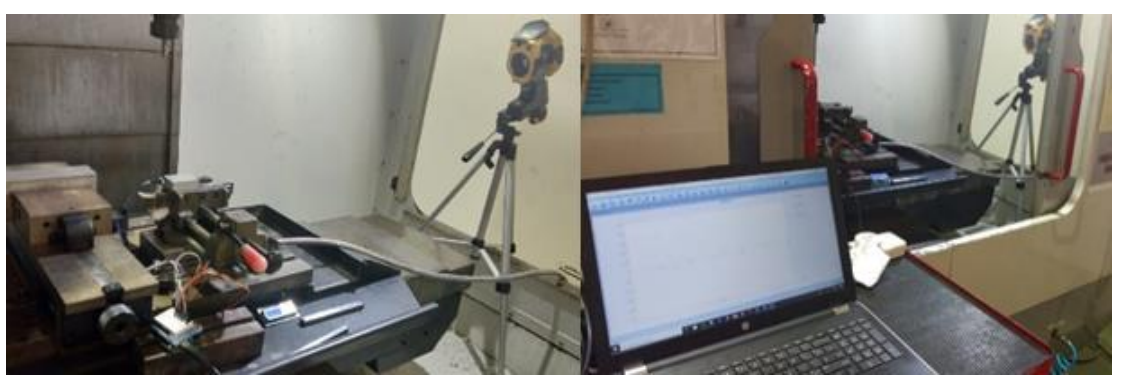

(a)

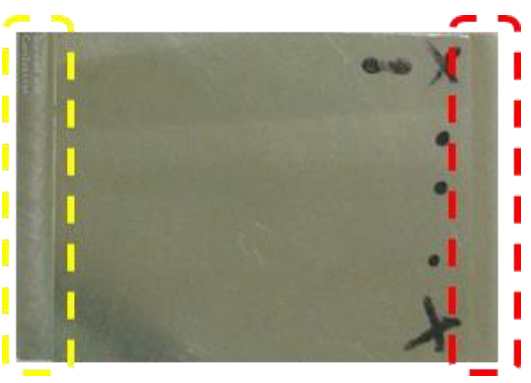

(b)

Fig. 8. (a) Measuring temperatures, (b) A specimen that derived the milling process

\section{Results}

This section presents experimental results of the two types of experiments performed; firstly, the temperature measurement validation and secondly the milling process heat temperature measurement itself. 


\subsection{Experimental Results}

The measurement consists of three processes in which each process consists of nine times of measurements on the AA6041 specimen.

\subsubsection{Temperature measurement}

Measurements of the heat temperature in AA6041 were carried out in nine sets of processes in which each process consists of three measurements as identified in Figure 3. The graphical representation of the data is shown in Figure 9 with MLX90614 (blue) and Fluke Ti400 (green) displaying an increasing trend where the deviation line shown at 0.1 scales.

Statistical analysis was applied to determine two measurements that were similar or different. Due to similar properties of the two measurements, the temperature measurement results were based only on the average value from of the nine experiments data collected as shown in Table 3. As shown by result of no. 6 , the deviation value at 0.08 is most significant. This indicates that MLx 90614 infrared thermometer is very accurate in measurement and can thus be employed as temperature measurement device on solid material through contactless approach.

Table 3

Temperature measurement (in ${ }^{\circ} \mathrm{C}$ ) on AA6014 by MLX90614 and Fluke Ti4000 with 0.72 emissivities

\begin{tabular}{llllllllll}
\hline No. & \multicolumn{1}{l}{ MLX90614 } & \multicolumn{3}{l}{ FLUKE Ti400 } & \multicolumn{3}{l}{$\begin{array}{l}\text { MLX90614 } \\
\text { Average }\end{array}$} \\
\cline { 2 - 8 } & 1 & 2 & 3 & 1 & 2 & 3 & & FLUKE Average Deviation \\
\hline 1 & 68.14 & 68.98 & 70.92 & 68.10 & 68.30 & 70.90 & 69.35 & 69.10 & 0.25 \\
2 & 100.34 & 101.40 & 106.00 & 100.70 & 101.70 & 106.40 & 102.58 & 102.93 & 0.35 \\
3 & 126.30 & 125.42 & 125.00 & 126.70 & 125.60 & 125.80 & 125.57 & 126.03 & 0.46 \\
4 & 134.70 & 138.50 & 137.32 & 134.50 & 138.30 & 136.30 & 136.84 & 136.37 & 0.47 \\
5 & 153.50 & 157.70 & 160.14 & 153.00 & 156.40 & 160.50 & 157.11 & 156.63 & 0.48 \\
6 & 173.42 & 177.70 & 183.32 & 173.40 & 177.50 & 183.80 & 178.15 & 178.23 & 0.08 \\
7 & 190.60 & 191.60 & 190.70 & 190.50 & 191.50 & 190.10 & 190.97 & 190.70 & 0.27 \\
8 & 211.40 & 212.20 & 216.22 & 211.40 & 212.10 & 216.90 & 213.27 & 213.47 & 0.19 \\
9 & 216.40 & 222.58 & 221.60 & 216.30 & 222.10 & 221.50 & 220.19 & 219.97 & 0.23 \\
\hline
\end{tabular}

Results above show that temperature measurements of MLX90641 were closely similar to the temperature measurement of Fluke Ti400. The average accuracy value of each measurement was \pm 2 ${ }^{\circ} \mathrm{C}$. Results in Figure 9 shows regular increment in temperature by both sensors. The red line in this chart refers to the deviation line whereby it looks more significant in test no.6. The result was exaggerated by the small scale of 0.1 in deviation that was selected. Less deviations were recorded as the temperature increases beyond $173.42{ }^{\circ} \mathrm{C}$. This showed that MLX90614 gave more accurate readings at high temperature range. The results indicate close association of the measurement data using Fluke Ti400 and infrared MLX90614. This conclude that the measurement data collected using the infrared MLX90614 is significant and accurate. 


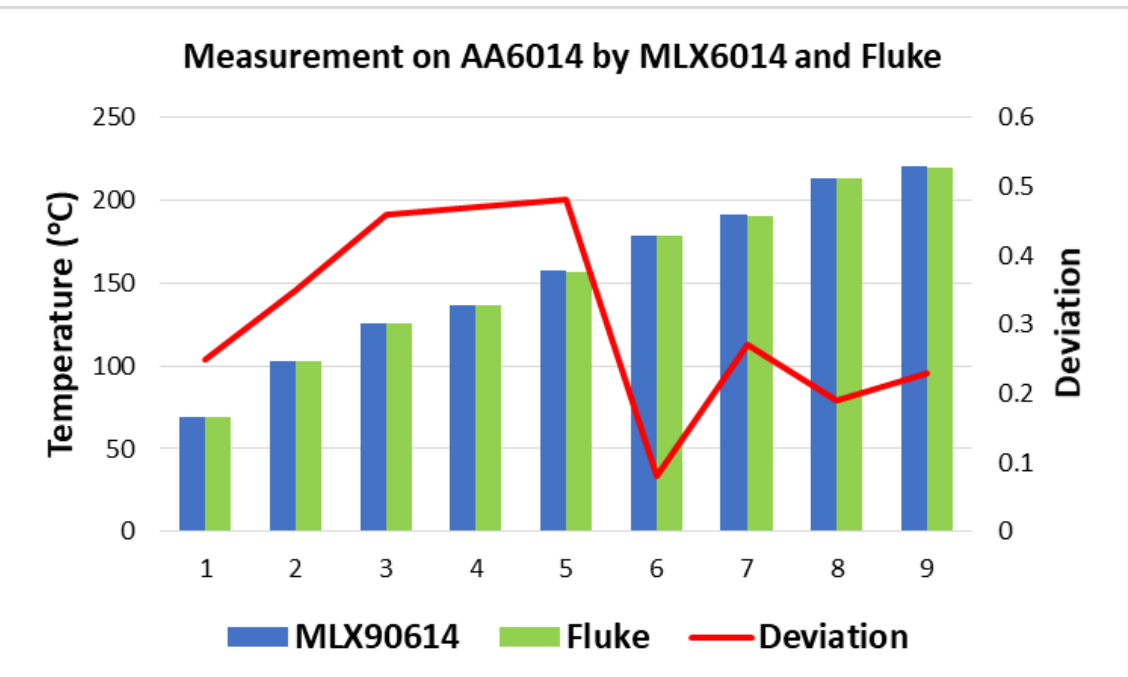

Fig. 9. Graph of the average measurement result between MLX90614 and Fluke Ti400

\subsubsection{Smart temperature measurement on AA6041 in milling process}

Two different sets of milling process parameters were identified and selected for the purpose of validation. As previously shown in Figure $8(\mathrm{~b})$, the left side refers to the milling process for measurement-1 parameters while the right side refers to the milling process for the measurement- 2 parameters. Table 4 and 5 are the machining parameters selected. The parameters differences were with regard to the feeding speed and depth of cut only. The results of the experiment were tabulated in Table 6.

Table 4

Cutting parameters for measurement-1

\begin{tabular}{lll}
\hline Parameters & Values & Units \\
\hline Vc & $220(7006)$ & $\mathrm{m} / \mathrm{min}(\mathrm{rpm})$ \\
Vf & $1146(\mathrm{fz}=0.041)$ & $\mathrm{mm} / \mathrm{min}(\mathrm{mm} /$ tooth $)$ \\
Doc & 0.3 & $\mathrm{~mm}$ \\
Woc & 4.0 & $\mathrm{~mm}$ \\
$\mathrm{Z}$ & 4 & tooth \\
\hline
\end{tabular}

Table 5

Cutting parameters for measurement-2

\begin{tabular}{lll}
\hline Parameters & Values & Units \\
\hline Vc & $220(7006)$ & $\mathrm{m} / \mathrm{min}(\mathrm{rpm})$ \\
Vf & $150(\mathrm{fz}=0.0053)$ & $\mathrm{mm} / \mathrm{min}(\mathrm{mm} /$ tooth $)$ \\
Doc & 0.5 & $\mathrm{~mm}$ \\
Woc & 4.0 & $\mathrm{~mm}$ \\
$\mathrm{Z}$ & 4 & tooth \\
\hline
\end{tabular}

Results of the temperature measurement in the two sets of the milling processes on AA6041 using MLX90614 (Table 6) and Fluke Ti400 (Figure 10) proved the capability of MLX90614 to be employed as a temperature measurement system in dry condition machining utilizing. Arduino and using Microsoft Excel as direct medium of analysis. 
Table 6

Measurement by MLX90614

\begin{tabular}{|c|c|c|c|}
\hline \multicolumn{2}{|c|}{ (a) Measurement-1 } & \multicolumn{2}{|c|}{ (b) Measurement-2 } \\
\hline Time Stamp & $\begin{array}{l}\text { Temperature } \\
\text { Value }\left({ }^{\circ} \mathrm{C}\right)\end{array}$ & Time Stamp & $\begin{array}{l}\text { Temperature } \\
\text { Value }\left({ }^{\circ} \mathrm{C}\right)\end{array}$ \\
\hline 1 & 23.74 & 1 & 26.68 \\
\hline 2 & 23.76 & 2 & 26.76 \\
\hline 3 & 23.76 & 3 & 26.82 \\
\hline 4 & 23.92 & 4 & 26.86 \\
\hline 5 & 23.88 & 5 & 26.92 \\
\hline 6 & 23.98 & 6 & 27.00 \\
\hline 7 & 23.86 & 7 & 27.04 \\
\hline 8 & 23.94 & 8 & 27.06 \\
\hline 9 & 24.00 & 9 & 27.18 \\
\hline 10 & 24.10 & 10 & 27.40 \\
\hline 11 & 24.04 & 11 & 27.52 \\
\hline 12 & 24.00 & 12 & 27.66 \\
\hline 13 & 24.06 & 13 & 27.82 \\
\hline 14 & 24.24 & 14 & 27.82 \\
\hline 15 & 24.22 & 15 & 27.88 \\
\hline 16 & 24.40 & 16 & 27.88 \\
\hline 17 & 24.58 & 17 & 27.72 \\
\hline 18 & 24.66 & 18 & 27.60 \\
\hline 19 & 24.60 & 19 & 27.48 \\
\hline 20 & 24.72 & 20 & 27.30 \\
\hline 21 & 24.58 & 21 & 27.24 \\
\hline 22 & 24.52 & 22 & 27.06 \\
\hline 23 & 24.30 & 23 & 27.00 \\
\hline 24 & 24.24 & 24 & 26.98 \\
\hline 25 & 24.18 & 25 & 26.98 \\
\hline 26 & 24.22 & 26 & 26.92 \\
\hline 27 & 24.10 & 27 & 26.94 \\
\hline 28 & 24.06 & 28 & 26.92 \\
\hline 29 & 23.98 & 29 & 26.86 \\
\hline 30 & 23.88 & 30 & 26.86 \\
\hline
\end{tabular}

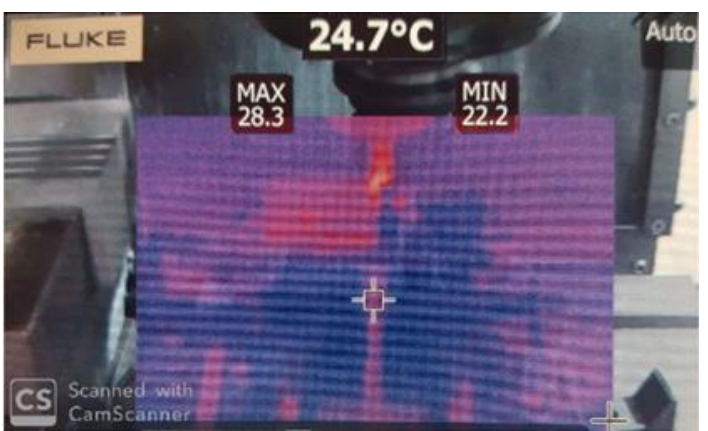

(a)

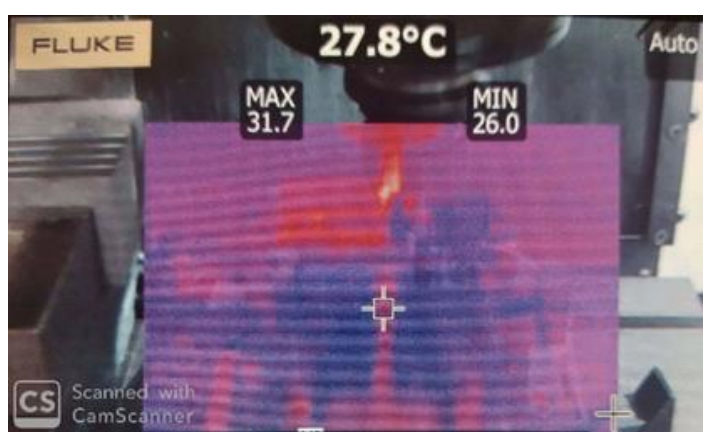

(b)

Fig. 10. (a) Measurement-1 by infrared fusion (b) Measurement-2 by infrared fusion

3.2 Temperature measurement analysis of MLX90614 Infrared Thermometer based on Arduino and Fluke Ti400

The first part of the experiment consist of nine runs. The temperature measurements of both MLX90614 and Fluke Ti400 were validated for accuracy. Results have shown that near-identical readings were obtained by both sensory units whereby specifically during sixth test, the average 
temperature recorded was $178.15^{\circ} \mathrm{C}$ and $178.23^{\circ} \mathrm{C}$ by MLX90614 and Fluke Ti400 respectively with smallest deviation at 0.08 . This measurement is considered very precise with respect to MLX 90614 for aluminum material in accordance with the measurement temperature range [18].

For the second part, the specimen AA6041 two-milling process temperature results indicate readings of $24.72{ }^{\circ} \mathrm{C}$ and $27.88^{\circ} \mathrm{C}$ using MLX90614 while results of $24.7^{\circ} \mathrm{C}$ and $27.8^{\circ} \mathrm{C}$ were recorded by Fluke Ti400. A near-identical temperature measurement results were obtained in both cases. A comparison between results in Table 6 and Figure 10 for MLX90614 and Fluke Ti400 respectively showed that both units achieved the same measurement with MLX90614 producing a more accurate result as measurement was based on the infrared radiation in the form of an electromagnetic wave [19]. Also, in term of uncertain value, the measurement at $150{ }^{\circ} \mathrm{C}$ average that refers to Table 6 has an uncertain value of 0.4765 .

The MLX90614 Infrared Thermometer and Arduino with link to Microsoft Excel was successfully designed and validated as a smart temperature measurement system for milling process. The advantage of this system is that it enables automatic temperature measurements of the CNC milling process of up to $350{ }^{\circ} \mathrm{C}$.

\section{Conclusions}

This paper presents the development of a smart milling process temperature measurement system based on a MLX90614 infrared thermometer coupled with Arduino microcontroller. The smart measurement system successfully recorded accurate measurement results on AA6041 specimen with as much as nine times with each time as many as three processes. The measurement results were validated for its accuracy against the infrared fusion Fluke Ti400 temperature sensor. The deviation data values range from 0.09 to 0.48 of the deviation scale. The temperature measurement system is permissible and feasible to be employed by researchers in machine tool applications in the field of manufacturing engineering. The automatic temperature measurement system with simultaneous data logging serves as a beneficial tool that can measure the temperature of the machined parts due to the impact of the milling process. Currently, to the best knowledge of the authors, no such loT-based system has been designed and applied for automatic measurement and recording of temperature during milling process. This application could be very well extended to other fields including medicine, robotics, plantation, education and others.

\section{Acknowledgement}

The authors would like to thank the Faculty of Manufacturing Engineering, Universiti Teknikal Malaysia Melaka (UTeM) for the facilities provided and Sekolah Tinggi Teknologi YBS Internasional for the support given.

\section{References}

[1] Kasim, M. S., M. S. A. Hafiz, J. A. Ghani, C. H. C. Haron, R. Izamshah, S. A. Sundi, S. B. Mohamed, and I. S. Othman. "Investigation of surface topology in ball nose end milling process of Inconel 718." Wear 426 (2019): 1318-1326. https://doi.org/10.1016/i.wear.2018.12.076

[2] Mohammad, Ayad Z. "Study on Enhancing Mechanical Properties of Tin Bronze Alloy Using Laser Technique." International Journal of Nanoelectronics and Materials 11, no. 4 (2018): 411-418.

[3] Zheng, Pai, Zhiqian Sang, Ray Y. Zhong, Yongkui Liu, Chao Liu, Khamdi Mubarok, Shiqiang Yu, and Xun Xu. "Smart manufacturing systems for Industry 4.0: Conceptual framework, scenarios, and future perspectives." Frontiers of Mechanical Engineering 13, no. 2 (2018): 137-150. https://doi.org/10.1007/s11465-018-0499-5

[4] Karim, K., Noraiham Mohamad, R. L. Lim, Hairul Effendy Ab Maulod, Jeefferie Abd Razak, Mohd Asyadi Azam, Mohd Shahir Kasim, and Raja Izamshah. "Effect of Thermal Cycles on Physical and Tensile Properties of Newly Modified NR/EPDM Blend." Journal of Advanced Research in Fluid Mechanics and Thermal Sciences 52, no. 2 (2018): 223- 
231.

[5] Misnal, Mohd Fadthul Ikmal, Norizah Redzuan, Muhamad Nor Firdaus Zainal, Norhayati Ahmad, Raja Kamarulzaman Raja Ibrahim, and Linda Agun. "Air Temperature Measurement and Monitoring Inside Cold Plasma Treatment Reactor for Steel Wire Surface Cleaning Using Fiber Bragg Grating (FBG)." Journal of Advanced Research in Fluid Mechanics and Thermal Sciences 70, no. 1 (2020): 155-167. https://doi.org/10.1007/s11465-018-0499-5

[6] Marques, Gonçalo, and Rui Pitarma. "Non-contact infrared temperature acquisition system based on Internet of things for laboratory activities monitoring." Procedia Computer Science 155 (2019): 487-494. https://doi.org/10.1016/i.procs.2019.08.068

[7] Putu, Yuni N. Ni, and Jesi Pebralia. "Studi Penerapan Sensor MLX90614 Sebagai Pengukur Suhu Tinggi secara Nonkontak Berbasis Arduino dan Labview." Prosiding Simposium Nasional Inovasi dan Pembelajaran Sains (2015).

[8] Jin, Gang, Xiangyu Zhang, Wenqiang Fan, Yunxue Liu, and Pengfei He. "Design of non-contact infra-red thermometer based on the sensor of MLX90614." The Open Automation and Control Systems Journal 7, no. 1 (2015). https://doi.org/10.2174/1874444301507010008

[9] Valente, João, Juan Jesús Roldán, Mario Garzón, and Antonio Barrientos. "Towards Airborne Thermography via Low-Cost Thermopile Infrared Sensors." Drones 3, no. 1 (2019): 30. https://doi.org/10.3390/drones3010030

[10] Vega, Felipe Andrés Obando, Ana Paola Montoya Ríos, Jairo Alexander Osorio Saraz, Luis Gonzalo Vargas Quiroz, and Flávio Alves Damasceno. "Assessment of black globe thermometers employing various sensors and alternative materials." Agricultural and Forest Meteorology $284 \quad 107891$. https://doi.org/10.1016/i.agrformet.2019.107891

[11] Wijaya, Nur Hudha, Zanella Oktavihandani, Kunal Kunal, Elsayed T. Helmy, and Phong Thanh Nguyen. "The Design of Tympani Thermometer Using Passive Infrared Sensor." Journal of Robotics and Control (JRC) 1, no. 1 (2019): $27-$ 30. https://doi.org/10.18196/irc.1106

[12] Wang, Yanping, and Zongtao Chi. "System of wireless temperature and humidity monitoring based on Arduino Uno Platform." In 2016 Sixth International Conference on Instrumentation \& Measurement, Computer, Communication and Control (IMCCC), pp. 770-773. IEEE, 2016. https://doi.org/10.1109/IMCCC.2016.89

[13] Miah, Md Asaduzzaman, Mir Hussain Kabir, Md Siddiqur Rahman Tanveer, and M. A. H. Akhand. "Continuous heart rate and body temperature monitoring system using Arduino UNO and Android device." In 2015 2nd International Conference on Electrical Information and Communication Technologies (EICT), pp. 183-188. IEEE, 2015. https://doi.org/10.1109/EICT.2015.7391943

[14] Pawar, Prajakta A. "Heart rate monitoring system using IR base sensor \& Arduino Uno." In 2014 Conference on IT in business, Industry and Government (CSIBIG), pp. 1-3. IEEE, 2014. https://doi.org/10.1109/CSIBIG.2014.7057005

[15] Priyadarshini, Indira, G. Jhansi, Nallamilli PG Bhavani, N. Jayachitra, V. Karthikeyan, K. S. Ram Kumar, and K. S. Kumar. "Clean coal technology using inventive materials for monitoring SO 2 emissions in smart power plants." In American Institute of Physics Conference Series, vol. 2105, no. 1, p. 020005. 2019.

[16] Yang, Zhicheng, Parth H. Pathak, Mo Sha, Tingting Zhu, Junai Gan, Pengfei Hu, and Prasant Mohapatra. "On the feasibility of estimating soluble sugar content using millimeter-wave." In Proceedings of the International Conference on Internet of Things Design and Implementation, pp. 13-24. 2019. https://doi.org/10.1145/3302505.3310065

[17] T. Guide, "FLUKE Calibration," Fluke Corp., no. March, 2013.

[18] M. Family, Datasheet Single and Dual Zone Infra Red Thermometer in TO-39. Melexis, 2019.

[19] Zhang, Jing. "Development of a Non-contact Infrared Thermometer." In 2017 International Conference Advanced Engineering and Technology Research (AETR 2017), pp. 308-312. Atlantis Press, 2018. https://doi.org/10.2991/aetr$\underline{17.2018 .59}$ 